\title{
Multiculturalismo e literatura: as fronteiras do currículo oficial
}

\author{
Aline Akemi Nagata
}

\section{Resumo:}

A introdução de um currículo escolar único para o país é problemática quando consideramos as fronteiras multiculturais existentes. Apesar de ser considerado um país acima de qualquer preconceito, muitos deles estão camuflados nos parâmetros nacionais impostos pelo governo. Em relação ao ensino de Literatura, percebemos que as fronteiras são ainda maiores, já que este ainda se encontra pautado nos cânones, desconsiderando a riqueza cultural existente em outras esferas de circulação. Fato é, que junto com a introdução de um currículo único observam aqueles que o teceram, é necessário introduzir aspectos regionais que tornem o ensino mais rico e atenda às necessidades de cada público-alvo. No entanto, na própria forma de exposição do documento oficial, percebemos que esta não é uma abertura de fato.

\section{Palavras Chave:}

Literatura, ensino, multiculturalismo, currículo.

\begin{abstract}
:
The introduction of a unique scholarship curriculum for a country is problematic when we consider the multicultural frontiers. Despite of being considered a country above all prejudice, much of them are hidden in the national parameters imposed by the government. In relation to the teaching of Literature, we notice that the frontiers are bigger, though it is based on the canon, not considering the existent cultural richness in other forms of circulation. It is a fact that, joined with the introduction of a unique curriculum, observe the ones that wrote it, it is necessary to introduce some regional aspects which should turn the teaching richer and should consider the need of each target-public. However, in the way the official document is exposed, we notice that this is not an opening at all.
\end{abstract}

\section{Keywords:}

Literature, teaching, multiculturalism, curriculum.

Embora muito se tenha discutido nos últimos anos sobre o ensino de Literatura, essa discussão não tem obtido os avanços esperados. Pelo contrário, nos deparamos com um contexto em que os maiores debates nesse campo giram em torno da permanência ou não desse ensino no âmbito escolar. Isso se deve à falta de fins práticos em uma sociedade submetida a relações de poder que, por sua vez, se encontram voltadas às imposições de mercado (formação de mão-de-obra qualificada e afins).

De fato, na mente de muitos alunos, especialmente do Ensino Médio, que se vêem às voltas com leituras que objetivam o preenchimento de fichas na escola, ou ao cumprimento de uma imensa lista imposta pelos grandes vestibulares, a Literatura é mesmo amaldiçoada e inútil. Sem entrar no mérito da questão da situação desse ensino hoje, posto que muito conhecida, criticada e imutável, mesmo assim, pretende-se com essa discussão inicial defender uma posição dissonante dessas vozes: a necessidade de permanência da Literatura no currículo escolar do Ensino Médio. Não porque sirva para algum propósito mercadológico, nesse ponto parece até que preste um desserviço, já que ocupa o lugar da crítica aos mecanismos de coisificação do homem, tão caros à manutenção da sociedade capitalista. Nesse ponto reside a sua importância, seu caráter 
antialienante, de não-servidão aos mecanismos de imposição de poder:

A literatura confirma e nega, propõe e denuncia, apóia e combate, fornecendo a possibilidade de vivermos dialeticamente os problemas. Por isso é indispensável tanto a literatura sancionada quanto a literatura proscrita; a que os poderes sugerem e a que nasce dos movimentos de negação do estado de coisas predominante (CANDIDO, 1995: 243).

Reafirmada a necessidade de se ensinar Literatura, é preciso responder a uma importante questão: "A que Literatura estamos nos referindo?". Para tanto, na presente discussão, partiremos de uma análise sobre qual a Literatura pretendida pelo Governo Federal, expressa nos documentos oficiais do Ministério da Educação (doravante MEC), quais são: o documento Literatura, escrito por Osakabe e Frederico (2004) e as Orientações Curriculares para o Ensino Médio (doravante OCEM): Literatura (2006) e, a partir dessa discussão, colocaremos em debate a introdução dos estudos multiculturais nesse contexto, sua presença ou ausência nesses documentos e as implicações desses estudos no currículo escolar(1).

\section{O currículo nacional e suas implicações}

A Lei de Diretrizes e Bases da Educação (doravante LDB), de 1996, expõe a necessidade de implementação de um currículo nacional comum, suficientemente flexível para ser complementado por uma parte diversificada em que características regionais e locais devem ser inseridas conforme a demanda das mesmas.

De acordo com Berenblum (2003: 105), apoiando-se em Apple (1994) ao impor um currículo nacional comum, por mais flexível que possa parecer, introduz-se no sistema educacional mais um mecanismo de «controle e regulação», já que estes se transformam em parâmetros para a avaliação constante da «qualidade da educação», um dos pilares dessa medida.

Com isso, o Governo Federal impõe aos estados e aos municípios conteúdos mínimos, considerados «patrimônios universais da humanidade», que supostamente garantiriam a qualidade da oferta de ensino em todo o país. Mas afinal, o que faz parte desse patrimônio? De acordo com Moreira, o currículo nacional

tem sido um dos principais alvos de questionamento dos intelectuais críticos da educação. Esses conteúdos mínimos podem conduzir à valorização de padrões culturais considerados parte de uma cultura comum, nacional, contribuindo para o «fortalecimento de sentimentos de identidade nacional» (1996 apud Berenblum, Idem: 106, grifo nosso).

Nesse sentido, pensando na Literatura e considerando as palavras de Moreira, o primeiro passo para o estabelecimento de um currículo nacional que busque a «valorização da identidade nacional brasileira» é propor o ensino da Literatura nacional, apenas, o que de fato, acontece:

Pensamos que se deve privilegiar como conteúdo de base no ensino médio a «Literatura brasileira», porém não só com obras da tradição literária, mas incluindo outras, contemporâneas significativas. Nada impede, e é desejável, que «obras de outras nacionalidades», se isso responder às necessidades do currículo de sua escola, sejam também selecionadas (OCEM - Literatura, 2006: 73-4 - grifo nosso).

Nesse excerto podemos perceber o quanto as OCEM obedecem aos preceitos da LDB (1996), temos a «Literatura brasileira» como a base nacional comum e, as obras de «outras nacionalidades» como a parte diversificada do currículo. Não entraremos na discussão acerca da unanimidade da Literatura brasileira no currículo - apesar de acreditarmos ser importante que o aluno tenha contato com a riqueza literária, não importando a nação proveniente - pois, pressupomos que esse recorte se deva ao fato de os três anos do 
Ensino Médio serem insuficientes para um estudo sistemático de todas as obras pretendidas, quando se considera um contato baseado na historiografia literária.

Retomando a discussão, ainda nesse mesmo excerto, um ponto que mais chama a atenção aos interesses desse trabalho é a «legitimidade», isso porque, no decorrer dos OCEM, há uma recorrência de termos como «significativa»e «autorizada» em relação às produções artísticas, que demonstram a necessidade de que a Literatura presente na escola seja legitimada por alguém, quer seja pelo tempo, no caso dos cânones, quer pela crítica contemporânea no caso dos não-canônicos.

Nesse sentido afirmam "nem tudo que é escrito pode ser considerado literatura" (Idem: 55), fato com o qual concordamos, porém, ficam algumas dúvidas, como legitimar aquilo que não é canônico, para que possa estar presente na sala de aula? Ou mesmo, quem possui tamanho poder a ponto de ditar o que é bom e o que é ruim? Quais são os critérios para essa análise?

Antes de tentar responder a algumas dessas questões é útil discutir a posição que ocupam as produções culturais não-canônicas na sociedade contemporânea.

\section{As produções multiculturais e sua (des)valorização}

É de se estranhar o súbito interesse e valorização da diversidade em uma sociedade globalizada que mascara intenções de homogeneização cultural. De acordo com Maher "a pluralidade cultural sempre fez parte do mundo; o fato, em si, não é novidade. O que é novo é a atenção que ela vem recebendo, principalmente por parte de educadores" (2007: 258). Silva (2005) debate bem essa questão ao analisar a relação entre currículo e multiculturalismo.

Segundo o autor, o multiculturalismo nasce nos países do Norte como um movimento ambíguo, que preza tanto por uma reivindicação dos grupos dominados culturalmente, as chamadas minorias, quanto por uma solução aos problemas trazidos por essa diversidade na construção de uma identidade nacional homogênea. Em ambos os casos, seja em sua posição crítica, no caso da primeira tendência, seja em sua posição liberal, no caso da segunda, estão imbricadas as relações de poder que "obrigaram essas diferentes culturas raciais, étnicas e nacionais a viverem no mesmo espaço" (SILVA, op. Cit.: 85).

O grande avanço dos estudos multiculturais em relação às teorias críticas é a explicitação de que essas relações de poder instauradas na produção da diferença estão relacionadas não somente a questões de classe, como preconizavam as teorias críticas, mas também atentam para as desigualdades de gênero, raça e sexualidade.

Sendo assim, a luta das minorias é contra as relações de poder que impõem uma cultura privilegiada: «branca, masculina, européia e heterossexual» (SILVA, op. cit.: 88), ou seja, que torna comum uma cultura que não corresponde a todos.

As críticas a tal perspectiva, ainda de acordo com Silva provêm de grupos conservadores, tradicionais e progressistas. Os conservadores acreditam que o multiculturalismo é:

um «ataque aos valores da nacionalidade», da família, da «herança cultural comum». Em termos curriculares, o multiculturalismo, nessa visão, pretende substituir o estudo das «obras consideradas como de excelência da produção intelectual» ocidental pelas obras consideradas «intelectualmente inferiores» produzidas por representantes das chamadas "minorias" - negros, mulheres, homossexuais (SILVA, Ibidem: 89). 
Já os progressistas acreditam que a ênfase nas múltiplas identidades proporcionaria a fragmentação da «cultura nacional única e comum». Para o autor, ambas as perspectivas de crítica, deixam de ver que essa «cultura comum» confunde-se com a cultura dominante.

Berenblum atenta para a "necessidade de considerar as diferenças e, com elas, a existência de diversas subjetividades", e prossegue afirmando que a escola mantém uma tendência à homogeneização, de nivelamento de "alunos portadores de capitais culturais diferentes ao que a escola pretende transmitir" (op. cit.: 104), condenando-os ao fracasso ou ao abandono escolar.

\section{Um ensino multicultural pautado nos cânones?}

A partir das considerações da seção anterior retomamos a discussão acerca dos cânones. Ao elaborar uma forte crítica ao «cânon», por expressar somente uma cultura particular daqueles que ocupam um lugar cultural e socialmente privilegiado, estende-se, com os estudos multiculturais, uma discussão iniciada ainda nas teorias tradicionais do currículo, que viam a Literatura como um ensino supérfluo, desnecessário para a formação do trabalhador (SILVA, op. cit.), porém, neste caso, a Literatura, tal como ela é ensinada nas escolas, passa a ser vista como um cânon a ser derrubado. Em ambos os casos o ensino de Literatura está em declínio.

Dessa forma, a posição das OCEM não dialoga com essas novas questões trazidas para o âmbito dos estudos do currículo. Pelo contrário, parece mesmo ignorá-las:

Ao se tratar das orientações curriculares para o ensino de literatura, consideram-se, portanto, em primeiro plano, as criações poéticas, dramáticas e ficcionais da cultura letrada. Tal primazia visa a garantir a democratização de uma esfera de produção cultural pouco ou menos acessível aos leitores, sobretudo da escola pública, fora do ambiente escolar (OCEM:Literatura, 2007: 60)

Sob a máscara da garantia da qualidade do ensino e, partindo do pressuposto de que os alunos já têm contato com outras manifestações "não-letradas" fora da escola, as OCEM insistem em um ensino baseado nos cânones, mesmo admitindo o seu caráter histórico, muitas vezes ignorado pela escola:

Ainda relativamente à seleção dos textos, é importante lembrar que o cânone não é em si significativo: significa que uma obra, na sua trajetória, de quando surgiu até o momento contemporâneo de leitura, foi reiteradamente legitimada como elemento expressivo de sua época. O cânone não é estático, ele incorpora ou exclui obras em decorrência de algumas variáveis, sendo talvez a mais importante aquela dos «estudos críticos, em especial os estudos acadêmicos» (OCEM, 2007: 75 - grifo nosso).

Para Berenblum, os Currículos Nacionais servem como elementos de controle, daí a necessidade de constante avaliação do conhecimento do aluno em provas instituídas tanto pelo Governo Federal quanto pelos estados. E, tais avaliações prezam pelos "conteúdos chamados mínimos, que estão indicados nos currículos e que são considerados «patrimônio universal da humanidade»" (BERENBLUM, op. cit.: 105 - grifo da autora).

Nesse ponto chegamos ao impasse do ensino de Literatura baseado nesses documentos oficiais, mas que se busca multicultural. Isso porque, se as obras contemporâneas, especialmente as produzidas pelas minorias, não têm o suporte do tempo, que já as legitimaria qualitativamente falando, muito menos têm elas [as obras contemporâneas] quem o faça agora, já que a crítica contemporânea ainda não possui uma força tal que consiga impor qualquer autor ou obra recente como um novo cânone. Isso, claro, quando esta mesma crítica está preocupada em analisar as produções das minorias, o que nem sempre acontece. Ou seja, o ensino tal 
qual ele é hoje está contribuindo para silenciar as «vozes historicamente silenciadas» (Ibidem: 106).

Portanto, se, de acordo com as OCEM, é preciso «legitimar» uma obra literária antes de sua chegada à escola, quem fará esse papel de «legitimador» em uma sociedade não democrática em termos de classe social, gênero, raça e cor? Alguém que pertence a uma dessas minorias, que provavelmente seria deslegitimado pela classe dominante ou alguém da classe dominante que ignoraria a produção da minoria, sob a ameaça da cultura nacional comum?

\section{Literário e não-literário: uma fronteira social}

Iniciamos a discussão dessa seção com uma questão norteadora: como definir o que é literário do que não é literário?

As OCEM trazem essa mesma discussão ao citar Chiappini (2005). De acordo com essa autora, existem duas posições diversas no ensino de literatura, uma é a do professor «autoritário», que somente trabalha em sala de aula com autores canônicos, a outra é a do professor «libertário e democrático», que traz para a classe todo e qualquer tipo de texto. Ainda apoiando-se na autora, as OCEM relatam que quanto à posição conservadora existe uma continuidade da forma de aprendizagem desse professor, considerado um reprodutor de fórmulas pré-concebidas, já a posição libertária, assim chamada por desconstruir o cânone, esconderia em seu caráter democrático, demasiada tolerância aos produtos de massa, supondo uma atitude preconceituosa que vê no aluno a incapacidade de fruir produtos de qualidade.

No documento Literatura, que serviu de base para tecer as considerações elaboradas nas OCEM acima citadas, a mesma posição prevalece:

O resultado automático desse processo [de aviltamento do ensino] foi o rebaixamento de nível e de exigências de ensino, rebaixamento justificado por uma suspeita preocupação de adequar o ensino às condições do aluno. Trata-se de uma versão perversa do velho preconceito segundo o qual não se devem deitar pérolas aos porcos, ou seja, as classes subalternas só merecem um ensino à sua altura (OSAKABE; FREDERICO, 2004: 62).

De fato, essa posição é bastante defendida entre os estudiosos de Literatura, é preciso que o aluno tenha contato com obras de qualidade e não que, sob a máscara de uma suposta democracia, este mesmo aluno seja impedido previamente, por conta de seu local de nascimento ou situação financeira de conhecer e fruir tais obras. Mas quais são elas?

Sabemos por meio das palavras de Candido que:

Em nossa sociedade há fruição segundo as classes na medida em que um homem do povo está praticamente privado da possibilidade de conhecer e aproveitar a leitura de Machado de Assis ou Mário de Andrade. Para ele, «ficam a literatura de massa, o folclore, a sabedoria espontânea, a canção popular, o provérbio». Estas modalidades são importantes e nobres, mas é grave considerá-las como suficientes para a grande maioria que, devido à pobreza e à ignorância, é impedida de chegar às obras eruditas (1995: 256-7 - grifo nosso).

Portanto, a «literatura de massa», o «folclore», a «sabedoria espontânea», a «canção popular» e o «provérbio», de acordo com Candido não são cânones. Pelo contrário, são mecanismos utilizados por professores, a serviço de um sistema maior, que privam previamente o aluno do contato com «Machado de Assis» ou «Mário de Andrade», esses sim, cânones. 
Tal afirmação é um lugar-comum nos estudos literários, o problema é a apropriação que dela se faz nas OCEM, que partem dela para indagar: "Qual seria então o lugar do rap, da literatura de cordel, das letras de músicas e de tantos outros tipos de produção, em prosa ou verso, no ensino de literatura?" (2007: 56 - grifo nosso), e prosseguem respondendo que a sua importância, seu grau de significância dentro de determinado contexto não é suficiente para imprimir-lhes qualidade estética, cabendo esta à análise de críticos, como foi feito com os canônicos. Aliás, os critérios utilizados devem ser os mesmos aos quais são submetidos os textos canônicos:

Qualquer texto escrito, seja ele popular ou erudito, seja expressão de «grupos majoritários ou de minoria»s, contenha denúncias ou reafirme o «status quo, deve passar pelo mesmo crivo que se utiliza para os escritos canônicos»: Há ou não intencionalidade artística? A realização correspondeu à intenção? Quais os recursos utilizados para tal? Qual seu significado histórico-social? Proporciona ele o estranhamento, o prazer estético? (OCEM: Literatura, 2007: 57 - grifo nosso).

No contexto das OCEM, o que se quer é discernir um texto literário de um texto de consumo, todavia, a afirmação grifada acima permite múltiplas interpretações, pois, considerando a situação das minorias, suas produções estéticas devem passar pelo «mesmo crivo que se utiliza para os escritos canônicos». Situação impossível, na medida em que se trata de uma situação de produção completamente distinta.

Maher, ao discutir o conceito de «relativismo cultural» de Franz Boas, que defende a especificidade de cada cultura por ser resultado de fatores sócio-históricos irreprodutíveis, afirma que "nenhuma cultura pode ser julgada por padrões externos a ela" (op. cit.: 266). Reconhecendo o caráter híbrido de formação das culturas e sua constante relação de interpenetração, trazido pela perspectiva pós-moderna, atentamos para a discussão suscitada por esta afirmação. Como atribuir valor a uma produção que para a classe dominante constitui um fator de destruição de uma pretensa cultura nacional?

Ainda de acordo com a autora (Ibidem: 267-8) as posições multiculturais críticas ou a «interculturalidade», como prefere chamar, acreditam em uma formação escolar que atente para o «desvelar» das estratégias utilizadas para construir a superioridade de uma cultura em relação às outras, pois, todo o conhecimento deve ser considerado e não somente o pertencente à classe dominante.

Nesse ponto, então, afirmamos que a fronteira entre o considerado literário e o não-literário, excetuando as produções de massa e seu baixo valor estético em qualquer esfera, é muito mais social do ponto de vista da relação maioria e minoria, do que estético, já que este critério ainda não tem sido convenientemente adotado para a análise das obras literárias contemporâneas.

\section{Considerações finais}

Pudemos perceber a partir dessa breve análise dos documentos oficiais do Governo Federal, em relação ao ensino de Literatura, que estes não abrem qualquer brecha às produções regionais, não canônicas - porque não têm a oportunidade de assim serem designadas - tal qual solicita a LDB, de 1996.

Um ensino de Literatura pautado nos cânones, que visa à formação plena do aluno, à humanização, ao contato do mesmo com obras de valor inestimável socialmente, as quais não obteria fora do ambiente escolar, esconde uma boa intenção, a da formação do sujeito social, crítico. Todavia, centrar o ensino somente em obras já consagradas é também privar este mesmo aluno de ter contato com produções culturais contemporâneas, além de produções multiculturais às quais ele também não terá contato fora do ambiente escolar.

Nesse sentido, ao colocar os cânones em patamares altíssimos, as OCEM o fazem passar por uma «cultura 
nacional comum», ou seja, fazem pensar que «essa é a excelência da produção intelectual nacional», sem nem ao menos considerar outras produções contemporâneas que contribuem para a formação do nacional, híbrido.

Para Silva,

Da perspectiva multiculturalista não existe nenhuma posição transcendental, privilegiada, a partir da qual se possam definir certos valores ou instituições como universais. Essa posição é sempre enunciativa, isto é, ela depende da posição de poder de quem a afirma, de quem a enuncia (op. cit.: 90).

As OCEM, ainda em seu julgamento de valor de produção nacional, também confundem os conceitos de cultura de massa com cultura popular. Fazem o leitor-professor pensar que tudo o que não é canônico é produção de massa. Contradizem-se ao considerar o cordel, por exemplo, como uma produção acessível aos alunos, portanto inferior em relação aos cânones e, afirmar que, na cultura popular, muitos textos são "capazes de proporcionar fruição estética" (OCEM: Literatura, 2007: 59). Seguindo esse raciocínio, erroneamente se concluiria que o cordel não seria uma produção cultural popular.

De qualquer forma, acreditamos em Silva quando este afirma que

a igualdade depende de uma modificação substancial do currículo existente. Não haverá 'justiça curricular', para usar uma expressão de Robert Connell, se o cânon curricular não for modificado para refletir as formas pelas quais a diferença é produzida por relações sociais de assimetria (op. cit.: 90).

Todavia, é preciso que se faça uma mudança substancial no currículo e não nas produções literárias, como bem atenta Chiappini (2001), para que não se produzam Literaturas engessadas em prol do «politicamente correto», "porque a literatura sempre deixou dialogar a contradição e tematizou os estereótipos. Mas se a policiarmos, engessaremos o que ela tem de criativo e que possibilitou isso".

Portanto, deixamos o apelo para a manutenção sim, do ensino de Literatura na escola no Ensino Médio, não como preparatório para o Vestibular, não pautado totalmente no livro didático, não seguindo demasiadamente os parâmetros da historiografia literária, ou seja, um ensino não «engessado», mas que seja múltiplo em sua forma de lidar, em suas situações de ensino, em sua escolha. Que reflita as preocupações, aflições de uma sociedade híbrida e que, por assim o ser, abra as portas para o novo, o desconhecido, o culturalmente superior, todavia socialmente inferiorizado.

\section{Bibliografia:}

BERENBLUM, Andra. A invenção da palavra oficial: identidade, língua nacional e escola em tempos de globalização. Belo Horizonte: Autêntica, 2003.

BRASIL. Secretaria de Educação Básica. Orientações curriculares nacionais para o ensino médio. Volume 1: Linguagens Códigos e suas Tecnologias. Brasília: MEC/SEB, 2006.

CANDIDO, Antonio. O direito à literatura. In: Vários escritos. 3. ed. São Paulo: Duas Cidades, 1995.

CHIAPPINI, Lígia. Multiculturalismo e identidade nacional. São Paulo: Revista de Literatura, CULT/46, 2001. Disponível em: www.celpcyro.org.br/multi_identNacional.htm. Acesso em: 27/07/2006.

MAHER, Tereza. A educação do entorno para a interculturalidade e o plurilingüísmo. In: KLEIMAN, A.; CAVALANTI, M.C. (orgs.). Lingüística aplicada - suas faces e interfaces. Campinas: Mercado de Letras, 2007. 
OSAKABE, Haquira; FREDERICO, Enid Yatsuda. Literatura. Orientações curriculares do ensino médio. Brasília: MEC/SEB/DPPEM, 2004.

SILVA, Tomaz Tadeu da. Documentos de identidade: uma introdução às teorias do currículo. 2.ed. $8^{\mathrm{a}}$ reimp. Belo Horizonte: Autêntica, 2005.

\section{Notas:}

(1) Apesar de mencionarmos em algumas passagens o contexto do Ensino Fundamental, nosso interesse no presente trabalho se encontra no Ensino Médio, por ser esse o momento de estudo sistemático da Literatura, objeto de nossa discussão.

\section{Mini Currículo :}

Graduada em Letras pela Universidade de Mogi das Cruzes. Atualmente é mestranda no Programa de Lingüística Aplicada, do Instituto de Estudos da Linguagem, da Universidade Estadual de Campinas. E-mail: kemi.nagata@gmail.com. 